\title{
Antiglycative effect of fruit and vegetable seed extracts: inhibition of AGE formation and carbonyl-trapping abilities
}

\author{
Marta Mesías a*, Marta Navarroa, Vural Gökmen and Francisco J. Moralesa
}

\author{
a Institute of Food Science, Technology and Nutrition, ICTAN-CSIC, E-28040 Madrid, Spain \\ b DepartmentofFoodEngineering,HacettepeUniversity,Beytepe,Ankara,Turkey
}

\begin{abstract}
BACKGROUND: Advanced glycation end-products (AGEs) are the final products derived from the nonenzymatic glycation process. AGEs are involved in the development of several health complications associated with diabetes and aging. Searching for anti- AGE extracts is necessary to mitigate the effects of age-related pathologies.

RESULTS: The antioxidant and antiglycative activities of eight aqueous extracts of fruit and vegetable seeds were evaluated. All seed extracts $(3.6 \mathrm{mg} \mathrm{mL}-\mathrm{I})$ exhibited anti-AGE activity in protein-glucose assay, ranging from 20 to $92 \%$ inhibition compared with aminoguanidine $(4.87 \mathrm{mmol} \mathrm{L}-\mathrm{I})$. Green pepper extract exerted the highest anti-AGE activity. However, peach and pomegranate extracts exhibited the highest anti-AGE activity in protein-methylglyoxal assay, ranging from 0 to $79 \%$ inhibition. Hazelnut, almond and sesame extracts were not effective when methylglyoxal was the promoter. Apricot and peach extracts appeared to inhibit the formation of AGEs through their capacity for direct trapping of I,2-dicarbonyls $(\mathrm{IC} 50=0.14 \mathrm{mg} \mathrm{mL}-\mathrm{I})$. No relationship between antioxidant and phenolic compound content and antiglycative activity was found. Therefore other hydrophilic constituents in addition to phenolic acids must be involved in the antiglycative activity of the extracts.

CONCLUSION: Aqueous extracts of fruits and vegetables can be considered in the prevention of glycation-associated complications of age-related pathologies.
\end{abstract}

KEYWORDS: advanced glycation end-products (AGEs); seed extract; glycation; glycation inhibitors; phenolic compounds

\section{INTRODUCTION}

The Maillard reaction or non-enzymatic glycation process is produced by the interaction between reducing sugars and free amino groups of proteins, lipids and nucleic acids. In the human body the final products that derive from this reaction are called advanced glycation end-products (AGEs). AGEs are a group of complex and heterogeneous products that can be classified according to their structures and characteristics as fluorescent crosslinking AGEs such as pentosidine, non-fluorescent crosslinking AGEs such as methylglyoxal-lysine dimer (MOLD) and non-crosslinking AGEs such as carboxymethyllysine $(\mathrm{CML})$ and pyrraline. I

It is known that AGEs are involved in the development of several health disorders such as diabetes and its complications, 2 atherosclerosis,3 Alzheimer's disease and normal aging.4 For this reason, the search for AGE formation inhibitors has recently received much attention.5-8 Various AGE inhibitors have been developed in the last few years, which can be divided into three groups: (I) inhibitors that prevent glycoxidation through metal ion chelation; (2) I,2-dicarbonyl-trapping agents; (3) crosslink breakers.9 Several AGE inhibitors have been described, a few of them exerting their effects at the early stage of glycation but most of them preventing the formation of AGEs at the late stage of glycation. Inhibition can occur through interference with the initial attachment between reducing sugars and amino groups, through trapping of carbonyls and radicals formed during glycation or through blocking the formation of intermediate Amadori products. 10 Aminoguanidine (AG) and pyridoxamine (PM) are well-known AGE 
inhibitors, both being considered as potent carbonyl scavengers. However, although such synthetic compounds have proved to be strong AGE inhibitors, they have also been associated with several adverse effects in in vivo assays. II, 12 Therefore the search for natural products with the ability to inhibit AGE formation is currently being widely pursued.

Many plant extracts have been evaluated for their inhibitory effects on the formation of AGEs, both through preventing glycoxidation and by scavenging reactive 1,2-dicarbonyls such as methylglyoxal (MGO), which are important precursors of AGEs.6,13,14 Most studies have been carried out in methanolic, ethanolic or other organic solvents, $7,13,15$ since the inhibitory effects are mainly attributed to polyphenols owing to their potent antioxidant activities. 16 It is known that phenolic compounds possess strong antioxidant abilities as a result of their redox properties; moreover, it has been reported that such antioxidant effects might contribute to the inhibition of protein modifications in the glycation process. 17 Among these studies, only a few have evaluated aqueous extracts of samples. 18, 19.

In this regard, the aim of the present study was to investigate the inhibitory effects on AGE formation of aqueous extracts from eight different fruit and vegetable seeds considered as secondary by-products in the industry. For this purpose, different in vitro models of AGEs induced by glucose and MGO were evaluated. Samples were extracted in water, since, despite the fact that the antiglycative effect of aqueous extracts might be lower than that of organic solvent extracts, the extraction procedure is both more economical and environmentally friendly and therefore would be of greater interest for industrial applications. The extracts were also tested for their capacity in direct trapping of MGO. Moreover, antioxidant activity and phenolic compound content were examined in order to study their possible relationship with AGE-inhibitory activity.

\section{MATERIALS AND METHODS}

Commercially available fruit and vegetable seeds (green pepper, apricot, hazelnut, peach, sour cherry, sesame, almond and pomegranate) were provided by TIKTA (Ankara, Turkey). Detailed information on the different samples is listed in Table I. D(+)-Glucose, bovine serum albumin (BSA), $400 \mathrm{~g} \mathrm{~L}-\mathrm{I}$ methylglyoxal solution (MGO), sodium azide, aminoguanidine ( $A G)$, 5-methylquinoxaline (5-MQ), ophenyldiamine (OPD), gallic acid, Trolox, fluorescein and phenolic acid standards were purchased from Sigma (St Louis, MO, USA). Sodium dihydrogen phosphate monohydrate, glacial acetic acid, formic acid and high-performance liquid chromatography (HPLC)-grade methanol were acquired from Merck (Darmstadt, Germany). Folin-Ciocalteu reagent and sodium carbonate were obtained from Panreac Quimica (Barcelona, Spain). 2,2- Azobis(methylpropionamidine)dihydro (AAPH) and pyridoxamine (PM) were purchased from Fluka Chemical (Madrid, Spain). A Pierce bicinchoninic acid (BCA) protein assay kit was obtained from Thermo Scientific (Rockford, IL, USA). The Milli-Q water used was produced using an Elix 3 water purification system coupled to an Advantage I0 Milli-Q module (Millipore, Molsheim, France). All other chemicals and reagents were of analytical grade.

\section{Preparation of seed extracts}

Powder $(500 \mathrm{mg})$ of each seed sample was extracted in water $(25 \mathrm{~mL} \times 2)$ at $50 \circ \mathrm{C}$ by agitation for 10 min each time. Pellets of the extracts were removed by centrifugation $(\mathrm{I} 400 \times \mathrm{g})$ and supernatants were collected, lyophilised and weighed. Soluble extracts were coded as described in Table I.

\section{Measurement of $\mathrm{pH}$}

Each lyophilised extract $(250 \mathrm{mg})$ was mixed with $10 \mathrm{~mL}$ of water and vortexed for $3 \mathrm{~min}$. The mixture was held at room temperature for I $\mathrm{h}$ to separate solid and liquid phases. After carefully removing the supernatant layer, the $\mathrm{pH}$ was measured using a CG-837 pH meter (Schott, Mainz, Germany). 


\section{Determination of soluble protein}

Soluble protein measurements were performed using a modified BCA protein assay. 20 According to Thermo Scientific, BCA protein assay reagent $A$ contains sodium carbonate, sodium bicarbonate, BCA and sodium tartrate in $0.1 \mathrm{~mL} L-I$ sodium hydroxide, while reagent $B$ contains $40 \mathrm{~g} L-I$ cupric sulfate. $B C A$ working reagent was prepared by mixing 50 parts of reagent $A$ and one part of reagent $B$. For sample analysis, $10 \mathrm{mg}$ of lyophilised extract was dissolved in $1 \mathrm{~mL}$ of phosphate buffer $(0.1 \mathrm{~mol} \mathrm{L-I}, \mathrm{pH}$ 7.4) and vortexed for $10 \mathrm{~min}$. The mixture was held at room temperature for $\mathrm{I} \mathrm{h}$ and centrifuged at $8000 \times \mathrm{g}$ for $10 \mathrm{~min}$. A $50 \mu \mathrm{L}$ aliquot of the supernatant was mixed with $500 \mu \mathrm{L}$ of BCA working reagent. After incubation for $90 \mathrm{~min}$ at $37 \circ \mathrm{C}$, the absorbance at $562 \mathrm{~nm}$ was recorded using a Synergy $\square$ HT-multimode microplate spectrophotometer (BioTek Instruments, Winooski, VT, USA) and quantified using BSA as a standard. BioTek Gen5 $\square$ data analysis software was used. The limit of quantification was set at $5.15 \mathrm{mg} \mathrm{g}-\mathrm{I}$ sample.

\section{Determination of reducing sugars}

Reducing sugars were determined according to the method described by Miller.2I A calibration curve was constructed using standard glucose solutions in the concentration range $0.25-2 \mathrm{mg} \mathrm{mL}-\mathrm{I}$. Each lyophilised extract $(50 \mathrm{mg})$ was suspended in $5 \mathrm{~mL}$ of distilled water at $50{ }^{\circ} \mathrm{C}$, vortexed for $20 \mathrm{~min}$ and centrifuged at $1400 \times \mathrm{g}$ for $15 \mathrm{~min}$ at $4 \circ \mathrm{C}$. The supernatant was collected. The extraction was repeated twice and the supernatants were pooled. Following treatment with Carrez-I and Carrez-II solutions, the supernatant was used to determine reducing sugars after blank correction. Results were expressed as $\mathrm{mg}$ glucose equivalent $\mathrm{g}-\mathrm{I}$ sample. The limit of quantification was set at $25.2 \mathrm{mg}$ glucose equivalent $\mathrm{g}-\mathrm{I}$ sample.

\section{Determination of total phenolic content}

Total phenolic content (TPC) in the extracts was determined by the Folin-Ciocalteu method as described by Singleton et al.22 and adapted to a plate reader. Each lyophilised extract was dissolved in water to obtain a $10 \mathrm{mg} \mathrm{mL}-1$ solution. In a $1.5 \mathrm{~mL}$ Eppendorf microtube, $100 \mu \mathrm{L}$ of sample (appropriately diluted if necessary) and $250 \mu \mathrm{L}$ of Folin-Ciocalteu reagent (diluted I:I (v/v) in methanol) were mixed and vortexed. After exactly $3 \mathrm{~min}, 500 \mu \mathrm{L}$ of $75 \mathrm{gL}-1$ sodium carbonate solution and $4 \mathrm{~mL}$ of methanol/water $(50: 50 \mathrm{v} / \mathrm{v})$ were added, then the mixture was vortexed for a further $10 \mathrm{~min}$ and allowed to stand at room temperature in darkness for $60 \mathrm{~min}$. The absorbance at $750 \mathrm{~nm}$ was recorded using a BioTek microplate spectrophotometer as described above and quantified using gallic acid as a standard. Results were expressed asmg gallic acid equivalent (GAE) g-I sample. The limit of quantification was set at $4.5 \mathrm{mgGAE}$ g-I sample.

\section{Determination of total extracted phenolic acids}

Total extracted phenolic acids were determined according to the method described by Kim et al.23 and Ross et al.24 First, I $\mathrm{mL}$ of $2 \mathrm{~mol} \mathrm{L-I}$ sodium hydroxide containing $13.4 \mathrm{mmol} \mathrm{L}-\mathrm{I}$ ethylenediaminetetraacetic acid (EDTA) and $20 \mathrm{~mL} \mathrm{~L}-I$ ascorbic acid was added to $30 \mathrm{mg}$ of each lyophilised extract. The mixture was flushed with nitrogen and allowed to hydrolyse under agitation for I6hat room temperature. After hydrolysis, the sample was centrifuged at $2370 \times \mathrm{g}$ for $10 \mathrm{~min}$ at $4 \circ \mathrm{C}$ and the supernatant wasacidifiedbyadding $0.3 \mathrm{mLof}$ acetic acid. The liberated phenolic acids were extracted with ethyl acetate $(2 \times 2 \mathrm{~mL})$. The organic layer containing the phenolic acids liberated by base hydrolysis was collected by pipetting off the upper organic (supernatant) layer from the bottom aqueous residue layer. The two organic layers were combined and evaporated to dryness in a speed-vac for $\mathrm{I} \mathrm{h}$ at $45{ }^{\circ} \mathrm{C}$. The residue was dissolved in $1 \mathrm{~mL}$ ofmethanol/water $(75: 25 \mathrm{v} / \mathrm{v})$ and filtered through a $0.45 \mu \mathrm{m}$ filter, then the sample was analysed by HPLC. Quantification was conducted with a Shimadzu HPLC system (Kyoto, Japan) equipped with an LC-20AD pump, an SIL-IOADvp autosampler, a CTO-IOASVP oven and an SPD-M20A diode array detector. Chromatographic separation was carried out on a Kinetex C-18 $100^{\circ} \mathrm{A}$ column ( $100 \mathrm{~mm} \times 4.6 \mathrm{~mm}, 2.6 \mu \mathrm{m}$; Phenomenex, Torrance, CA, USA). The flow 
rate was $0.6 \mathrm{~mL}$ min-I and the injection volume was $5 \mu \mathrm{L}$. The mobile phase consisted of $I \mathrm{~mL} L-I$ formic acid in water (solvent $A$ ) andmethanol (solvent $B$ ) and the gradient program was as follows: 0 min, 25\% B; 0-5 min, 25-30\% B; 5-10 min, 30-60\% B; 10-12 min, 60\% B; 12-13 min, 60-80\% B; I3-14 $\min , 80 \% \mathrm{~B}$; $14-15 \mathrm{~min}, 80-25 \% \mathrm{~B}$; $15-18 \mathrm{~min}, 25 \% \mathrm{~B}$. The total run time was 18 min and chromatograms were analysed at 254, 280 and $325 \mathrm{~nm}$. The following phenolic acids were identified: $\mathrm{p}-$ hydroxybenzoic acid (PHB), syringic acid (SYN), vanillic acid (VA), P-coumaric acid (PCU), caffeic acid (CA), ferulic acid (FA), protocatechuic acid (PCA), gallic acid (GA), gentisic acid (GE), sinapinic acid (SIN) and ellagic acid (EA). The limit of quantification was set at $2 \mu g \mathrm{~g}-\mathrm{I}$ sample.

\section{Determination of benzoic acids}

The presence of benzoic acids was determined using the HPLC method described by Lamuela-Raventos and Waterhouse.25 Procedures for sample preparation, quantification and chromatographic separation were the same as those described for total extracted phenolic acid determination. The total run time was $18 \mathrm{~min}$ and quantification was made at $280 \mathrm{~nm}$ (expressed as gallic acid). The limit of quantification was set at $2.5 \mu \mathrm{g}$ GAE g-I sample.

\section{Determination of flavonoids}

Flavonoid content was determined using the aluminium chloride method described by Abdel-Hameed.26 Each lyophilised extract was dissolved in water at $25 \mathrm{mg} \mathrm{mL}-\mathrm{I}$. Then $80 \mu \mathrm{L}$ of sample was mixed with $80 \mu \mathrm{L}$ of aluminium trichloride in ethanol and $100 \mu \mathrm{L}$ of sodium acetate. The mixture was incubated in darkness for $90 \mathrm{~min}$ and centrifuged at $14926 \times \mathrm{g}$ for $3 \mathrm{~min}$. Flavonoids were determined based on the formation of a flavonoid-aluminium complex with absorptivity maximum at $440 \mathrm{~nm}$. Absorbance readings were taken using aBioTek microplate spectrophotometer as described above. Quercetin was used as a reference standard. Results were expressed as $\mu \mathrm{g}$ quercetin equivalent per $100 \mathrm{~g}$ sample. The limit of quantification was set at $0.02 \mu \mathrm{g}$ quercetin equivalent per $100 \mathrm{~g}$ sample.

\section{ORAC assay}

Alkylperoxyl free radical (ROO•)-scavenging activity was measured by monitoring the fluorescence decay due to ROO-induced oxidation of fluorescein, known as the oxygen radical absorbance capacity (ORAC) assay. The water-soluble azo initiator AAPH was applied as a clean and controllable source of thermally produced ROO• in aqueous media. ROO - were generated by AAPH in a microplate reader at $37 \circ \mathrm{C}$. The antiradical activity against AAPH was estimated according to the procedure reported by D'avalos et al.27 A BioTek Synergy $\square$ HT-multimode microplate reader with automatic reagent dispense and temperature control was used. All reaction mixtures were prepared in duplicate and four independent assays were performed for each sample. Raw data were processed by the microplate reader, and the area under the curve (AUC) was calculated. ORAC was expressed as Trolox equivalent antioxidant capacity (TEAC) using a standard curve constructed for each assay. Results were expressed as $\mu \mathrm{mol}$ TEAC $\mathrm{g}-\mathrm{I}$ sample. The limit of quantification was set at I8.I $\mu \mathrm{mol}$ TEAC $\mathrm{g}-\mathrm{I}$ sample.

\section{ABTS assay}

Antioxidant activity was estimated in terms of the radical scavenging activity of samples in aqueous media following the procedure described by Delgado-Andrade and Morales 28 with slight modification. 2,2 -Azino-bis(3-ethylbenzothiazoline-6-sulfonic) acid radical cations (ABTS•+) were produced by reacting $7 \mathrm{mmol} L-I$ ABTS stock solution with $2.45 \mathrm{mmol} \mathrm{L}-\mathrm{I}$ potassium persulfate and allowing the mixture to stand in the dark at room temperature for 12-16 h before use. The ABTS + solution (stable for 2 days) was diluted with distilled water to an absorbance of $0.70 \pm 0.02$ at $734 \mathrm{~nm}$. Each lyophilised extract was dissolved in water at $10 \mathrm{mg} \mathrm{mL}-\mathrm{I}$. Following the addition of $40 \mu \mathrm{L}$ of sample (appropriately diluted if necessary) and Trolox standard to $200 \mu \mathrm{L}$ of water and $40 \mu \mathrm{L}$ of diluted ABTS•+ solution, an absorbance reading was taken after 10 min using a Bio-Tek Synergy $\square$ HT-multimode microplate reader 
as described above. Aqueous solutions of Trolox at concentrations of $0.016-0.5 \mathrm{mmolL}-\mathrm{I}$ were used for calibration. The limit of quantification was set at $1.1 \mu \mathrm{mol}$ TEAC $g-I$ sample.

\section{In vitro glycation assay with BSA-glucose}

The BSA-glucose (Glc) assay was based on Peng et al.6 and was used as an in vitro model for comparison of the antiglycation activities of the different seed extracts. First, BSA $(35 \mathrm{mgmL}-\mathrm{I})$ and Glc (I75 mg mL-I) were dissolved separately in phosphate buffer (0.1 mol L-I, pH 7.4). Then $200 \mu \mathrm{L}$ of BSA solution containing $0.1 \mathrm{~g} \mathrm{~mL}-1$ sodium azide (to ensure aseptic conditions) was incubated with 400 $\mu \mathrm{L}$ of Glc solution at $37{ }^{\circ} \mathrm{C}$ for $2 \mathrm{I}$ days in the absence or presence of seed extract solutions ( $100 \mu \mathrm{L}, 25$ $\mathrm{mg} \mathrm{mL}-\mathrm{I}$ ). Blanks containing BSA-Glc but no test sample were kept at $-80 \circ \mathrm{C}$ until measurement. A 4 $\mathrm{mg} \mathrm{mL}-\mathrm{I}$ solution of $\mathrm{AG}(32.49 \mathrm{mmol} \mathrm{L}-\mathrm{I})$ was used as positive control, corresponding to $4.87 \mathrm{mmol}$ $\mathrm{L}-\mathrm{I}$ in the reaction media. In parallel, seed extracts dissolved in phosphate buffer $(0.1 \mathrm{~mol} \mathrm{~L}-\mathrm{I}, \mathrm{pH}$ 7.4) were incubated at $37{ }^{\circ} \mathrm{C}$ for 21 days in order to measure their intrinsic fluorescence. The final concentration of each reactant in the reaction medium was $10 \mathrm{mg} \mathrm{mL}-I$ for BSA, $100 \mathrm{mg} \mathrm{mL}-I$ for Glc, $0.6 \mathrm{mg} \mathrm{mL}-\mathrm{I}$ for $\mathrm{AG}$ and $3.6 \mathrm{mg} \mathrm{mL}-\mathrm{I}$ for seed extracts.

\section{In vitro glycation assay with BSA-MGO}

The BSA-MGO assay was performed according to the method described by Lunceford and Gugliucci29 with slight modification and was used to evaluate the inhibitory effects of the different seed extracts on protein glycation induced by MGO. First, BSA ( $35 \mathrm{mg} \mathrm{mL}-1)$ and MGO $(0.4 \mathrm{mg} \mathrm{mL}-\mathrm{I})$ were dissolved separately in

phosphate buffer $(0.1 \mathrm{~mol} \mathrm{~L}-\mathrm{I}, \mathrm{pH} 7.4)$. Then $200 \mu \mathrm{L}$ of BSA solution containing $0.1 \mathrm{~g} \mathrm{~mL}-\mathrm{I}$ sodium azide (to ensure aseptic conditions) was incubated with $400 \mu \mathrm{L}$ ofMGO solution at $37 \circ \mathrm{C}$ for 14 days in the absence or presence of seed extracts solutions ( $100 \mu \mathrm{L}, 25 \mathrm{mg} \mathrm{mL}-\mathrm{I}$ ). Blanks containing BSA-MGO but no test sample were kept at $-80 \circ \mathrm{C}$ until measurement. A $4 \mathrm{mg} \mathrm{mL}-I$ solution of $A G(32.49 \mathrm{mmol}$ $\mathrm{L}-\mathrm{I}$ ) was used as positive control, corresponding to $4.87 \mathrm{mmol} \mathrm{L}-\mathrm{I}$ in the reactionmedia. In parallel, seed extracts dissolved in phosphate buffer $(0.1 \mathrm{~mol} \mathrm{~L}-\mathrm{I}, \mathrm{pH} 7.4)$ were incubated at $37{ }^{\circ} \mathrm{C}$ for $\mathrm{I} 4$ days in order to measure their intrinsic fluorescence. The final concentration of each reactant in the reaction medium was $10 \mathrm{mg} \mathrm{mL}-\mathrm{I}$ for BSA, $0.23 \mathrm{mg} \mathrm{mL}-$ I for $\mathrm{MGO}, 0.6 \mathrm{mg} \mathrm{mL}-$ I for $\mathrm{AG}$ and $3.6 \mathrm{mg} \mathrm{mL}-\mathrm{I}$ for seed extracts.

\section{AGE fluorescence measurement}

Measurements of the fluorescent intensity of total AGEs and the intrinsic fluorescence of the different seed extracts after incubation were performed using a BioTek microplate spectrophotometer as described above. The presence of total AGEs was characterized by typical fluorescence with respective excitation and emission maxima at 360 and $420 \mathrm{~nm}$ for the BSA-Glc assay and 340 and $420 \mathrm{~nm}$ for the BSA-MGO assay. The percentage inhibition of AGE formation by each extract was calculated using the following equation: inhibition $(\%)=\{1-[($ fluorescence of solution with inhibitor - intrinsic fluorescence of sample)/fluorescence of solution without inhibitor]\} $\times 100$.

\section{Evaluation of direct MGO-trapping capacity}

Direct MGO-trapping capacity was tested using the method described by Peng et al.15 with slight modification. MGO (0.4 mg mL-I) was dissolved in phosphate buffer $(0.1 \mathrm{~mol} \mathrm{L-I}, \mathrm{PH} 7.4)$, OPD (derivatisation agent, $10.8 \mathrm{mg} \mathrm{mL}-\mathrm{I}$ ) was dissolved in methanol and 5-MQ (internal standard, I $\mathrm{mg}$ $\mathrm{mL}-\mathrm{I}$ ) was dissolved in $500 \mathrm{~mL} \mathrm{L-I}$ methanol. PM solution (I mg mL-I in $0.1 \mathrm{~mol} \mathrm{~L}-1$ phosphate buffer, $\mathrm{pH}$ 7.4) was used as positive control. A $100 \mu \mathrm{L}$ aliquot of MGO solution was mixed with $750 \mu \mathrm{L}$ of phosphate buffered saline (PBS), $50 \mu \mathrm{L}$ of $5-\mathrm{MQ}$ and $100 \mu \mathrm{L}$ of either PBS (blank), seed extract solutions $(0.005-10 \mathrm{mgmL}-1)$ or PM solution. Therefore the final concentration of each reactant in the reaction medium was $0.04 \mathrm{mg} \mathrm{mL}-\mathrm{I}$ for $\mathrm{MGO}, 0.1 \mathrm{mg} \mathrm{mL}-\mathrm{I}$ for $\mathrm{PM}$ and $0.0005-1 \mathrm{mg} \mathrm{mL}-\mathrm{I}$ for seed extracts. After mixing, samples were incubated at $37 \circ \mathrm{C}$ for $168 \mathrm{~h}$. Then controls and samples were taken out, $200 \mu \mathrm{L}$ of OPD was added and each mixture was shaken by vortex for $5 \mathrm{~s}$. After $30 \mathrm{~min}$ 
(when the derivatisation reaction was complete) the residual MGO was quantified on the basis of the amount of the derivatised product 2-methylquinoxaline (2- MQ) formed in each sample. Quantification was conducted using a Shimadzu HPLC system equipped with an LC-20AD pump, an SIL-I0ADvp autosampler, a CTO-IOASVP oven and an SPD-M20A diode array detector. Chromatographic separation was carried out on a Mediterranea-Sea-ODS2 column $(150 \mathrm{~mm} \times 3 \mathrm{~mm}, 5 \mu \mathrm{m}$; Tecknokroma, Barcelona, Spain). The flow rate was $0.5 \mathrm{~mL} \mathrm{min-I}$ and the injection volume was $10 \mu \mathrm{L}$. Isocratic elution was applied using a mobile phase of $5 \mathrm{~mL} \mathrm{~L}-I$ acetic acid/methanol $(50: 50 \mathrm{v} / \mathrm{v})$. The total run time was $7 \mathrm{~min}$ and chromatograms were recorded at $315 \mathrm{~nm}$. The amount of unreacted MGO in each sample could be determined on the basis of the ratio of peak areas of 2-MQ and 5-MQ. The percentage decrease in MGO was calculated using the following equation: MGO decrease (\%)=[(amount of MGO in control - amount of MGO in sample with tested seed extract solution or PM solution)/amount of MGO in control] $\times 100 \%$. IC50 values of samples were evaluated from the doseresponse curves of each experiment using Microsoft Excel.

\section{Statistical analysis}

Statistical analyses were performed using Statgraphics Centurion XV (Herndon, VA, USA). Data were expressed as mean \pm standard deviation (SD). Analysis of variance (ANOVA) and the least significant difference (LSD) test were applied to determine differences between means. Differences were considered to be significant at $P<0.05$. Relationships between the different parameters analysed were evaluated by computing Pearson linear correlation coefficients at the $P<0.05$ confidence level.

\section{RESULTS AND DISCUSSION}

As a first step, the solubility of each extract was evaluated. The extracts showed a wide range of solubility varying from from 129.8 to $478.1 \mathrm{mg} g-1$, with pomegranate and green pepper seeds being least soluble and peach, apricot and almond seeds being most soluble (Table I). Similarly, a wide variability in the $\mathrm{pH}$ of the extracts was observed when the lyophilised samples were reconstituted in water at a concentration of $25 \mathrm{mg} \mathrm{mL}-\mathrm{I}$, ranging from $\mathrm{pH} 4.0$ for green pepper extract to $\mathrm{pH} 8.5$ for pomegranate extract (Table 2).

Since sugars and proteins are reactants of the Maillard reaction and may be involved in the glycation process, reducing sugars and soluble proteins were analysed in the aqueous extracts. The highest reducing sugar content was observed in sour cherry extract (20I.I $\mathrm{mg} g-\mathrm{I})$, followed by peach $(136.1 \mathrm{mg} \mathrm{g}-\mathrm{I})$ and sesame $(124.0 \mathrm{mg} \mathrm{g}-\mathrm{I})$ extracts, while almond and hazelnut extracts exhibited the lowest values (4I.5 and $34.4 \mathrm{mg} \mathrm{g}-1$ respectively). Soluble protein content varied from $139.7 \mathrm{mg} \mathrm{g}-1$ in sesame extract to $383.3 \mathrm{mg} \mathrm{g}-1$ in hazelnut extract (Table 2).

The antioxidant activities of the aqueous extracts were assessed by two methods: the ORAC assay and the ABTS assay (free radical-scavenging capacity). Table 2 shows the analytical results. The capacity to scavenge O2 - radicals ranged from $107.4 \mu \mathrm{mol}$ TEAC g-I extract for peach to $6378 \mu \mathrm{mol}$ TEAC g-I extract for pomegranate, a huge difference. Similarly, the ABTS results varied markedly, ranging from 4.6 to $232.7 \mu \mathrm{mol}$ TEAC g-I extract. Pomegranate extract had the highest free radical-scavenging activity, followed by green pepper extract, while sour cherry and apricot extracts showed the lowest scavenging activity. No significant correlation was found between ORAC and ABTS, but the capacity of certain extracts such as those of pomegranate and green pepper to scavenge O2- radicals was related to their capacity to scavenge ABTS radicals.

Since phenolic compounds have been proposed as major contributors to antiglycative activity, 6 they were also determined (Table 2). TPC varied from $4.8 \mathrm{mg}$ GAE g-I in apricot extract to $22.2 \mathrm{mg}$ GAE $\mathrm{g}-\mathrm{I}$ in pomegranate extract. The proportion of individual phenolic acids in the total extracted phenolic acids was also evaluated (Table 3). Among these phenolic acids, one can note the significant 
contributions of caffeic acid in apricot extract (41.3\%), ferulic acid in sesame extract (39.9\%) and gallic acid in pomegranate extract (39.8\%).

With the aim of finding other compounds present in the extracts that may be involved in antiglycative activity, benzoic acids and flavonoids were also determined. Benzoic acid content ranged from 3.5 to 7.9 mg GAE g-I extract, with almond and pomegranate extracts having the lowest and highest content respectively (data not shown). Flavonoid content was lower than the limit of quantification $(0.02 \mu \mathrm{g}$ quercetin equivalent per $100 \mathrm{~g}$ sample) for all extracts except that of pomegranate, whose content was $0.29 \mu \mathrm{g}$ quercetin equivalent per $100 \mathrm{~g}$ sample (data not shown).

In order to evaluate the inhibitory effect of seed extracts against AGE formation in vitro, the fluorescence intensity was measured using $A G$ as an $A G E$ inhibitor. Figures IA and IB display the inhibitory effects at $25 \mathrm{mg} \mathrm{mL}-1$ on AGE formation in BSA-Glc and BSA-MGO assays respectively (final concentration in reaction medium $3.6 \mathrm{mgmL}-1$ ). The results indicated significant differences in AGEinhibitory activity among most samples $(P<0.05)$. In BSA-Glc assay the AGE-inhibitory rate ranged from 20.7 to $91.9 \%$. Green pepper exhibited the highest inhibitory capacity with a value close to the effect of AG solution (average inhibitory rate $92.7 \%$ ), followed by sesame and pomegranatewith 66.1 and $61.7 \%$ inhibition respectively. The lowest inhibitory activity was observed for peach and apricot with 20.7 and $23.2 \%$ inhibition respectively. In contrast, both peach and apricot, together with pomegranate, resulted inmorethan60\%reduction intheformation offluorescent AGEs in BSA-MGO assay, whereas sesame, hazelnut and almond had no inhibitory activity. In this assay the AGE-inhibitory rate of seed extracts ranged from 0 to $78.6 \%$, with the highest values being lower than the effect of AG solution (average inhibitory rate $99.2 \%$ ).

Several inhibitors can suppress AGE formation by scavenging certain precursors such as 1,2-dicarbonyls. An evaluation of direct MGO-trapping capacity was carried out in order to observe whether our tested seed extracts could directly scavenge these compounds. Figure 2 shows the different trapping abilities of the samples. All aqueous extracts trapped MGO in a dose-dependent manner and, with the exception of hazelnut and sesame, their activity at a concentration of $10 \mathrm{mg} \mathrm{mL}-1$ was comparable to or higher than the effect of I mg mL-I PM solution (99.6\%). The values for IC50 (mg mL-I) are presented in Table 4. As can be observed, apricot and peach had the lowest IC50 $(0.14 \mathrm{mg} \mathrm{mL}-1)$, followed by sour cherry $(0.48 \mathrm{mg} \mathrm{mL}-1)$, associated with their high MGO-trapping capacity. In contrast, sesame and hazelnut had the highest IC50, corresponding to their low MGO trapping capacity (Fig. 2). As expected, IC50 from MGO-trapping assay was negatively correlated with antiglycative activity from BSA-MGO assay $(r=-0.890, P=0.003)$. In this sense, peach and apricot exhibited the lowestlC50 by MGO-trapping assay and, at the same time, the highest antiglycative activity by BSA-MGO assay together with pomegranate. In contrast, no relation was found for pomegranate between IC50 from MGO-trapping assay and antiglycative activity from BSA-MGO assay. Regarding BSA-Glc assay, no relationship was found between IC50 and anti-AGE capacity according to this assay $(P>0.05)$.

In the present study it has been demonstrated that aqueous extracts of fruit and vegetable seeds possess antiglycative activity. In addition, the samples displayed concentration-dependent MGO-trapping ability. However, as mentioned above, some of the extracts were found to be inhibitors of AGE formation in BSA-Glc assay, whereas little or no effect was observed when these samples were subjected to BSAMGO assay (Fig. I). Since inhibitors of glycation can act in multiple steps, it is important to apply different scenarios such as BSA-Glc and BSA-MGO assays to reach a conclusion on their anti-AGE ability. Consequently, both positive and negative inhibitory effects should not be discounted.

In previous studies, several authors have found correlations between TPC and the inhibitory effect on AGE formation of different extracts.6,7 The possible association of AGE inhibition and antioxidant 
activity was analysed in our assays. No correlation between ORAC or ABTS and antiglycative activity was found in either BSA-Glc or BSA-MGO assay. Regarding the phenolic compound content, it was not correlated with anti-AGE activity in either absolute or relative amounts. Similar results have been observed by Povichit et al., I3 who reported that extracts of certain medicinal plants exhibited high antiglycative activity although they had low phenolic content. In accordance with Sun et al.,7 such absence of correlation suggests that phenolic compounds are not the sole antiglycative agents of the selected seed extracts and therefore other compounds present in the samples must be involved in their anti-AGE ability. It should be taken into account

that most authors have investigated the preventive effect on AGE formation through extraction of samples with various organic solvents, which are more efficient than water for extracting phenolic compounds.30 As mentioned above, we carried out our assays using aqueous extracts, which might justify the lack of relationship between phenolic composition and antiglycative activity of the extracts.

Another factor to consider is the individual phenolic acid composition in the different aqueous extracts. In this sense, $\mathrm{Wu}$ et al.3I evaluated the ability of dietary phenolic acids to inhibit glucose-mediated protein glycation. The authors concluded that at a concentration of I mmol L-I most phenolic acids inhibited the glycation process, with vanillic, gallic and ferulic acids being the most significant inhibitors. According to these results, the high inhibitory activity of sesame and pomegranate in BSA-Glc assay could be explained, as their major phenolic acids were ferulic acid and gallic acid respectively (Table 3, Fig. IA). Recently, Muthenna et al.32 reported ellagic acid to be a potent antiglycating agent in a protein-sugar system, which, together with gallic acid, could explain the high antiglycative activity of pomegranate extract. Regarding green pepper, its anti-AGE ability in this system could be associated mainly with its ellagic acid content, but in addition with its ferulic acid and phydroxybenzoic acid content, which, although at lower intensity, has also been found to be an antiglycative agent.3I The antiAGE effect of the compounds, however, depends on the tested concentrations; thus low, high or no antiglycative activity has been described for ferulic acid at different incubation conditions in proteinsugar model systems. 19,33,34 In the BSA-MGO system, Gugliucci et al.35 reported high AGE inhibition by caffeic acid. This may justify apricot extract showing on eof the highest antiglycative activities in the present study (Fig. IB), but it does not justify pomegranate or peach extract activity. It should be highlighted that, in accordance with Chompoo et al.,5 the presence of more than one inhibitor in an extractmayhave a synergistic effect. In this way, Rice-Evans et al.36 reported that phenolic compounds may have antagonistic or synergistic effects with themselves or with other constituents of a sample, which may justify the diversity found among the results of the present study. To the best of our knowledge, antiglycative effects of sesame, green pepper, apricot andpeach seeds have not been reportedbefore. Regarding pomegranate seed, anti-glycative ability associated with its free radicalscavenging property has been reported by Rout and Banerjee.37

\section{CONCLUSIONS}

Eight aqueous extracts of fruit and vegetable seeds were evaluated for their antiglycative activity using different in vitro models. All extracts exhibited positive inhibitory effects on the formation of AGEs in BSA-Glc assay, although to different extents. However, BSA-MGO assay and direct MGO-trapping assay showed that some extracts exerted their activity through a different mechanism of action. Aqueous extracts of peach, pomegranate and apricot seeds appeared to inhibit the formation of AGEs through their capacity for trapping I,2-dicarbonyls. These findings are relevant for focusing on potential extracts to combat the main promoters of aging in humans. On the other hand, no relationship between antioxidant and phenolic compound content and antiglycative activity of the extracts was found. This finding leads us to conclude that other hydrophilic constituents in addition to phenolic acids must be involved in the antiglycative activity of the aqueous seed extracts. Isolation and characterisation of different target compounds are undercurrent investigation by advanced structural identification methodologies. 


\section{ACKNOWLEDGMENT}

This research is funded by the Ministry of Science and Innovation (Spain) under project NATURAGE (AGL20 I 0- I7779). M Navarro is grateful for a JAE-predoc grant from CSIC.

\section{LITERATURE CITED}

I Rahbar S andFigarola JL, Inhibitors andbreakersof advancedglycation endproducts (AGEs): a review. CurrMedChemlmmunolEndocrMetab Agents 2:135-161 (2002).

2 Vlassara $\mathrm{H}$ and Palace MR, Diabetes and advanced glycation endproducts. J InternMed 25I:87-10I (2002).

3 Vlassara H, Advanced glycation end-products and atherosclerosis. Ann Med 28:419-426 (1996).

4 M"unch G, Thome J, Foley P, Schinzel R and Riederer P, Advanced glycation endproducts in ageing and Alzheimer's disease. Brain Res Rev 23:134-143 (1997).

5 Chompoo J, Upadhyay A, Kishimoto W, Makise T and Tawata S, Advanced glycation end products inhibitors from Alpinia zerumbet rhizomes. Food Chem 129:709-7I5 (201 I).

6 Peng X, Cheng KW, Ma J, Chen B, Ho CT, Lo C, et al, Cinnamon bark proanthocyanidins as reactive carbonyl scavengers to prevent the formation of advanced glycation endproducts. J Agric Food Chem 56:1907-19|I (2008).

7 Sun Z, Peng X, Liu J, Fan KW, Wang M and Chen F, Inhibitory effects of microalgal extracts on the formation of advanced glycation endproducts (AGEs). Food Chem 120:26I-267 (2010).

8 Wang X, Zhang LS and Dong LL, Inhibitory effect of polysaccharides from pumpkin on advanced glycation end-products formation and aldose reductase activity. Food Chem 130:82I-825 (2012).

9 Reddy VP and Beyaz A, Inhibitors of the Maillard reaction and AGE breakers as therapeutics for multiple diseases. Drug Discov Today II:646-654 (2006).

10 Peng $X$, Ma J, Chen F and Wang M, Naturally occurring inhibitors against the formation of advanced glycation endproducts. Food Funct 2:289-30I (201 I).

II Thornalley PJ, Use of aminoguanidine (Pimagedine) to prevent the formation of advanced glycation end products. Arch Biochem Biophys 419:31-40 (2003).

12 Williams M, Clinical studies of advanced glycation end product inhibitors and diabetic kidney disease. Curr Diabetes Rep 4:44I-446 (2004).

I3 Povichit N, Phrutivorapongkul A, Suttajit M, Chaiyasut CC and Leelapornpisid P, Phenolic content and in vitro inhibitory effects on oxidation and protein glycation of some Thai medicinal plants. Pak J Pharmaceut Sci 23:403-408 (2010).

14 Wang J, Sun B, Cao $Y$ and Tian Y, Protein glycation inhibitory activity of wheat bran feruloyl oligosaccharides. Food Chem II 2:350-353 (2009). 
I5 Peng X, Zheng Z, Cheng KW, Shan F, Ren GX, Chen F, et al, Inhibitory effect of mung bean extract and its constituents vitexin and isovitexin on the formation of advanced glycation endproducts. Food Chem 106:475-48I (2008).

16 Ahmad MS and Ahmed N, Antiglycation properties of aged garlic extract: possible role in prevention of diabetic complications. JNutr 136:796S-799S (2006).

$17 \mathrm{Wu} \mathrm{CH}$ and Ten GC, Inhibitory effect of naturally occurring flavonoids on the formation of advanced glycation endproducts. J Agric Food Chem 53:3167-3173 (2005).

I8 Nakagawa T, Yokozawa T, Teresawa K, Shu S and Juneja LR, Protective activity of green tea against free radical- and glucose-mediated protein damage. J Agric Food Chem 50:24I8-2422 (2002).

$19 \mathrm{Wu}$ JW, Hsieh CL, Wang HY and Chen HY, Inhibitory effects of guava (Psidium guajava L.) leaf extracts and its active compounds on the glycation process of protein. Food Chem I 13:78-84 (2009).

20 Smith PK, Krohn RI, Hermanson GT, Mallia AK, Gartner FH, Provenzano MD, et al, Measurement of protein using bicinchoninic acid. Anal Biochem 150:76-85 (1985).

21 Miller GL, Use of dinitrosalicylic acid reagent for determination of reducing sugars. Anal Chem $31: 426-428$ (1959).

22 Singleton VL, Orthofer R and Lamuela-Raventos RM, Analysis of total phenols and other oxidation substrates and antioxidants by means of Folin-Ciocalteu reagent. Meth Enzymol 299:152-I78 (1999).

$23 \mathrm{Kim} \mathrm{KH}$, Tsao R, Yang R and Cui SW, Phenolic acid profiles and antioxidant activities of wheat bran extracts and the effect of hydrolysis conditions. Food Chem 95:466-473 (2006).

24 Ross KA, Beta $T$ and Arntfield SD, A comparative study on the phenolic acids identified and quantified in dry beans using HPLC as affected by different extraction and hydrolysismethods. FoodChem I I3:336-344 (2009).

25 Lamuela-Ravent ' os RM and Waterhouse AL, A direct HPLC separation of wine phenolics. Am J Enol Vitic 45: I-5 (1994).

26 Abdel-Hameed ESS, Total phenolic contents and free radical scavenging activity of certain Egyptian Ficus species leaf samples. Food Chem I |4:I27I-I 277 (2009).

27 ' 'avalos A, G'omez-Cordov'es $C$ and Bartolom'e B, Extending applicability of the oxygen radical absorbance capacity (ORACfluorescein) assay. J Agric Food Chem 52:48-54 (2004).

28 Delgado-Andrade $\mathrm{C}$ and Morales FJ, Unraveling the contribution of melanoidins to the antioxidant activity of coffee brews. J Agric Food Chem 53:|403-I 407 (2005).

29 Lunceford $\mathrm{N}$ and Gugliucci A, llex paraguariensis extracts inhibit AGE formation more efficiently than green tea. Fitoterapia 76:419-427 (2005).

30 Lapornik B, Pro`sekMandWondraAG, Comparison of extracts prepared from plant by-products using different solvents and extraction time. J Food Eng 7I:2।4-222 (2005). 
3I Wu CH, Yeh CT, Shih PH and Yen GC, Dietary phenolic acids attenuate multiple stages of protein glycation and high-glucose-stimulated proinflammatory IL-I $\beta$ activation by interfering with chromatin remodeling and transcription in monocytes. Mol Nutr Food Res 54:127S-I40S (2010).

32 Muthenna P, Akileshwari $C$ and Reddy B, Ellagic acid, a new antiglycating agent: its inhibition of $N \varepsilon-$ (carboxymethyl)lysine. Biochem J 442:22I-230 (2012).

33 Bou`sov'a I,MartinJ, Jahod'a ǎrL,Dǔsek J, PalǐckaVandDr`sata J, Evaluation of in vitro effects of natural substances of plant origin using amodel of protein glycoxidation. J Pharmaceut Biomed Anal 37:957-962 (2005).

34 Silv 'an JM, Assar SH, Srey C, del CastilloMDand Ames JM, Control of the Maillard reaction by ferulic acid. Food Chem I28:208-213 (20II).

35 Gugliucci A, Bastos DHM, Schulze J and Souza MFF, Caffeic and chlorogenic acids in llex paraguariensis extracts are the main inhibitors of AGE generation by methylglyoxal in model proteins. Fitoterapia 80:339-344 (2009).

36 Rice-Evans CA,MillerNJ and PagangaG, Structure-antioxidant activity relationships of flavonoids and phenolic acids. Free Radic Biol Med 20:933-956 (1996).

37 Rout S and Banerjee R, Free radical scavenging, anti-glycation and tyrosinase inhibition properties of a polysaccharide fraction isolated from the rind from Punica granatum. Bioresour Technol 98:3159-3163 (2007). 
FIGURES AND TABLES

\section{Table 1}

Description of the tested seed samples and their solubility in water. ${ }^{\text {a }}$

\begin{tabular}{cllll}
\hline $\begin{array}{c}\text { Sample } \\
\text { extract ID }\end{array}$ & Common name & Scientific name & Family & $\begin{array}{c}\text { Soluble extract } \\
\left(\mathrm{mg} \mathrm{g}^{-1}\right)\end{array}$ \\
\hline $\mathrm{Gp}$ & Green pepper & Capsicum annuum & Solanaceae & $194.9 \pm 0.64 \mathrm{~b}$ \\
$\mathrm{Ap}$ & Apricot & Prunus armeniaca & Rosaceae & $445.8 \pm 22.27 \mathrm{de}$ \\
$\mathrm{Ha}$ & Hazelnut & Corylus avellana & Betulaceae & $436.2 \pm 17.04 \mathrm{~d}$ \\
$\mathrm{Pe}$ & Peach & Prunus persica & Rosaceae & $478.1 \pm 16.05 \mathrm{e}$ \\
$\mathrm{Sc}$ & Sour cherry & Prunus cerasus & Rosaceae & $257.1 \pm 29.27 \mathrm{c}$ \\
$\mathrm{Se}$ & Sesame & Sesamum indicum & Pedaliaceae & $224.6 \pm 8.06 \mathrm{bc}$ \\
$\mathrm{Al}$ & Almond & Prunus dulcis & Rosaceae & $442.8 \pm 15.77 \mathrm{de}$ \\
$\mathrm{Po}$ & Pomegranate & Punica granatum & Punicaceae & $129.8 \pm 4.31 \mathrm{a}$ \\
\hline
\end{tabular}

${ }^{\mathrm{a}}$ Results are expressed as mean $\pm \mathrm{SD}$ for $\mathrm{n}=3$. Different letters mean significant differences $(\mathrm{p}<0.05)$. 


\section{Table 2}

Characterization of the aqueous extracts from fruit and vegetable seeds. ${ }^{a}$

\begin{tabular}{ccccccc}
\hline $\begin{array}{c}\text { Sample } \\
\text { extract }\end{array}$ & $\mathrm{pH}$ & $\begin{array}{c}\text { Soluble protein } \\
\left(\mathrm{mg} \mathrm{g}^{-1}\right)\end{array}$ & $\begin{array}{c}\text { Reducing sugars } \\
\left(\mathrm{mg} \mathrm{g}^{-1}\right)\end{array}$ & $\begin{array}{c}\text { ORAC } \\
\left(\mu \mathrm{mol} \mathrm{TEAC} \mathrm{g}{ }^{-1}\right)\end{array}$ & $\begin{array}{c}\text { ABTS } \\
\left.(\mu \mathrm{mol} \mathrm{TEAC} \mathrm{g})^{-1}\right)\end{array}$ & $\begin{array}{c}\text { TPC } \\
\left(\mathrm{mg} \mathrm{GAE} \mathrm{g}^{-1}\right)\end{array}$ \\
\hline $\mathrm{Gp}$ & 4.0 & $219.0 \pm 10.3 \mathrm{~b}$ & $93.3 \pm 2.75 \mathrm{c}$ & $359.6 \pm 5.16 \mathrm{c}$ & $91.6 \pm 35.4 \mathrm{c}$ & $10.7 \pm 0.3 \mathrm{~d}$ \\
$\mathrm{Ap}$ & 4.5 & $282.0 \pm 19.1 \mathrm{~cd}$ & $71.5 \pm 0.67 \mathrm{~b}$ & $145.6 \pm 6.36 \mathrm{ab}$ & $8.9 \pm 2.1 \mathrm{a}$ & $4.8 \pm 0.2 \mathrm{a}$ \\
$\mathrm{Ha}$ & 5.5 & $383.3 \pm 42.3 \mathrm{e}$ & $34.4 \pm 0.30 \mathrm{a}$ & $144.7 \pm 2.83 \mathrm{ab}$ & $17.3 \pm 2.1 \mathrm{ab}$ & $10.2 \pm 0.8 \mathrm{~d}$ \\
$\mathrm{Pe}$ & 5.5 & $209.0 \pm 2.5 \mathrm{~b}$ & $136.1 \pm 3.42 \mathrm{e}$ & $107.4 \pm 14.28 \mathrm{a}$ & $10.4 \pm 2.3 \mathrm{a}$ & $8.8 \pm 0.2 \mathrm{c}$ \\
$\mathrm{Sc}$ & 5.5 & $330.3 \pm 28.5 \mathrm{de}$ & $201.1 \pm 5.29 \mathrm{f}$ & $300.4 \pm 0.35 \mathrm{c}$ & $4.6 \pm 1.6 \mathrm{a}$ & $7.3 \pm 0.7 \mathrm{~b}$ \\
$\mathrm{Se}$ & 6.5 & $139.7 \pm 8.3 \mathrm{a}$ & $124.0 \pm 0.01 \mathrm{~d}$ & $272.9 \pm 2.55 \mathrm{bc}$ & $42.7 \pm 2.6 \mathrm{~b}$ & $7.8 \pm 0.3 \mathrm{bc}$ \\
$\mathrm{Al}$ & 6.5 & $227.6 \pm 0.9 \mathrm{bc}$ & $41.5 \pm 0.29 \mathrm{a}$ & $124.7 \pm 1.56 \mathrm{a}$ & $24.3 \pm 5.7 \mathrm{ab}$ & $10.9 \pm 0.1 \mathrm{~d}$ \\
$\mathrm{Po}$ & 8.5 & $368.4 \pm 39.8 \mathrm{e}$ & $119.6 \pm 0.79 \mathrm{~d}$ & $6378 \pm 160.9 \mathrm{~d}$ & $232.7 \pm 16.1 \mathrm{~d}$ & $22.2 \pm 1.1 \mathrm{e}$ \\
\hline
\end{tabular}

${ }^{a}$ Gp: green pepper. Ap: apricot. Ha: hazelnut. Pe: peach. Sc: sour cherry. Se: sesame. Al: almond. Po: pomegranate. Results are expressed as mean \pm SD for $n=4$. Different letters mean significant differences $(p<0.05)$.

TPC: Total phenolic content. 


\section{Table 3}

Proportion of phenolic acids in each seed extract expressed as percentage. ${ }^{\text {a }}$

\begin{tabular}{cccccccccccc}
\hline Sample extract & PHB & SYN & VA & pCU & CA & FA & PCA & GA & GE & SIN & EA \\
\hline Gp & 24.0 & 2.1 & 5.2 & 5.2 & 5.6 & 18.7 & 9.6 & nd & nd & 5.1 & 24.4 \\
Ap & 3.0 & 1.8 & 4.8 & 13.5 & 41.3 & 26.7 & 5.7 & 0.7 & nd & 2.5 & nd \\
Ha & 5.6 & 10.4 & 32.0 & 4.7 & 1.2 & 3.2 & 22.2 & 15.4 & nd & 5.3 & nd \\
Pe & 21.5 & 7.7 & 1.9 & 17.5 & 2.4 & 17.2 & 28.0 & 1.7 & nd & 2.0 & nd \\
Sc & 20.1 & 3.5 & 1.1 & 16.3 & 20.8 & 3.3 & 14.7 & 4.1 & 12.2 & 4.0 & nd \\
Se & 7.7 & 2.6 & 0.4 & 30.1 & 11.3 & 39.9 & 4.6 & 0.1 & nd & 3.3 & nd \\
Al & 9.8 & 38.4 & 2.7 & 10.3 & 12.3 & 7.1 & 12.5 & 2.7 & nd & 4.3 & nd \\
Po & 11.8 & 8.8 & 0.1 & 8.3 & 1.6 & 4.5 & 4.2 & 39.8 & nd & 1.3 & 19.6 \\
\hline
\end{tabular}

${ }^{a}$ Gp: green pepper. Ap: apricot. Ha: hazelnut. Pe: peach. Sc: sour cherry. Se: sesame. Al: almond. Po: pomegranate. PHB: p-hydroxybenzoic. SYN: syringic acid. VA: vanillic acid. pCU: p-coumaric. CA: caffeic acid. FA: ferulic acid. PCA: protocatechuic acid. GA: gallic acid. GE: gentisic acid. SIN: sinapinic acid. EA: ellagic acid. nd $<2 \mu \mathrm{g} \mathrm{g}^{-1}$ sample 


\section{Table 4}

MGO trapping capacity of the different seed extracts. ${ }^{\text {a }}$

\begin{tabular}{cc}
\hline Sample extract & $\mathrm{IC}_{50}$ values $\left(\mathrm{mg} \mathrm{mL}^{-1}\right)$ \\
\hline $\mathrm{Gp}$ & 1.70 \\
$\mathrm{Ap}$ & 0.14 \\
$\mathrm{Ha}$ & 3.30 \\
$\mathrm{Pe}$ & 0.14 \\
$\mathrm{Sc}$ & 0.48 \\
$\mathrm{Se}$ & 2.65 \\
$\mathrm{Al}$ & 2.25 \\
$\mathrm{Po}$ & 1.60 \\
$\mathrm{PM}$ & 0.06 \\
\hline
\end{tabular}

${ }^{\text {a }}$ Gp: green pepper. Ap: apricot. Ha: hazelnut. Pe: peach. Sc: sour cherry.

Se: sesame. Al: almond. Po: pomegranate. PM: piridoxamine. 


\section{Figure captions}

Figure I. (A): Antiglycative activity of the different seed extracts on the formation of AGEs in BSA-glucose (Glc) assay. (B): Antiglycative activity of the different seed extracts on the formation of AGEs in BSA-methylglyoxal (MGO) assay. The concentration of each extract was $25 \mathrm{mg} \mathrm{mL}-1$ (final concentration in the reaction medium $3.6 \mathrm{mg} \mathrm{mL}^{-1}$ ). Results are expressed as mean \pm SD for $n=4$. Different letters mean significant differences $(p<0.05)$. AG solution (final concentration 0.6 $\mathrm{mg} \mathrm{mL}^{-1}$ ) presented an antiglycative activity of $92.7 \%$ and $99.2 \%$ for BSA-Glc and BSA-MGO assays, respectively. Green pepper (Gp), apricot (Ap), hazelnut $(\mathrm{Ha})$, peach $(\mathrm{Pe})$, sour cherry $(\mathrm{Sc})$, sesame (Se), almond (Al) and pomegranate (Po).

Figure 2. Dose-dependent results for MGO trapping capacity experiment at $168 \mathrm{~h}$ of the different seed extracts. (A) MGO scavenging abilities of green pepper (Gp), apricot (Ap), sour cherry (Sc) and hazelnut (Ha). (B) MGO scavenging abilities of peach (Pe), sesame (Se), almond (Al) and pomegranate (Po). Results are expressed as mean $\pm \mathrm{SD}$ for $\mathrm{n}=4$. PM solution (final concentration $0.1 \mathrm{mg} \mathrm{mL}^{-1}$ ) presented a MGO trapping capacity of $99.6 \%$. 
Figure 1
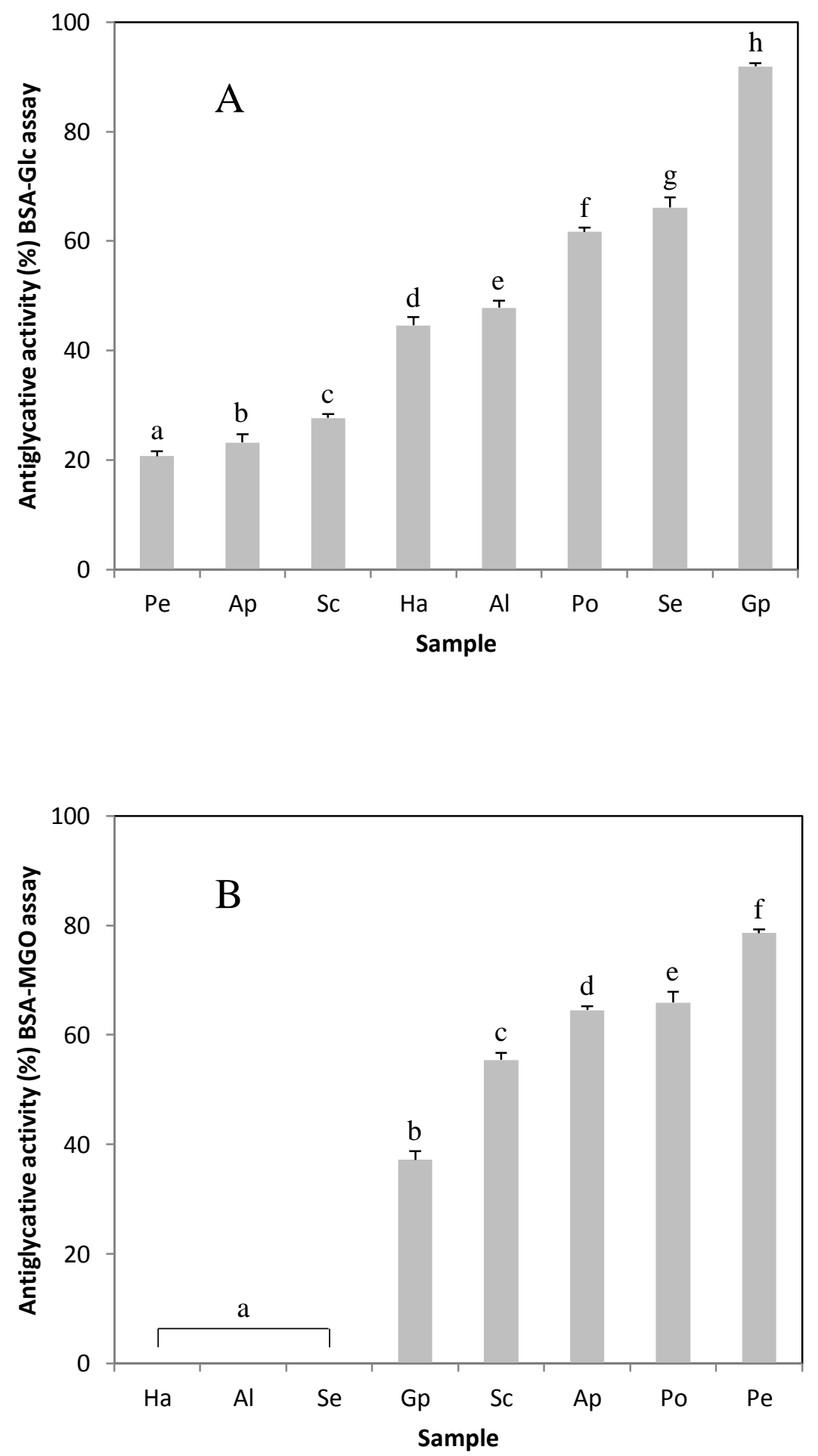
Figure 2
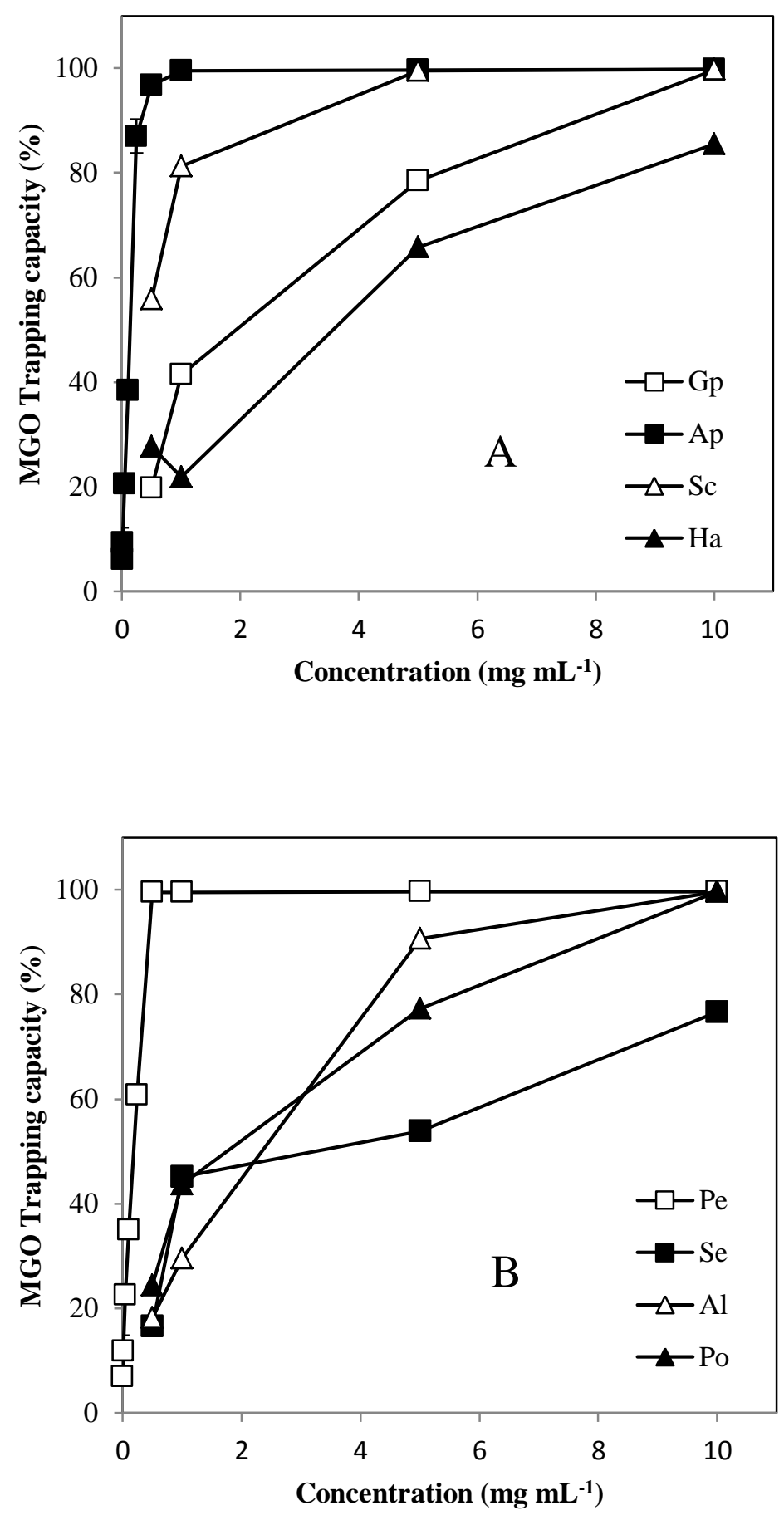